\title{
A CRIAÇÃO DO GRUPO \\ ESCOLAR SILVEIRA BRUM E \\ SEUS PRIMEIROS ANOS DE \\ FUNCIONAMENTO: RELAÇÓES \\ ENTRE A REPÚBLICA E AS FESTAS \\ ESCOLARES (1912-1930).
}

Este artigo versa sobre aspectos referentes ao processo de criaçáo e os primeiros anos de funcionamento do primeiro Grupo Escolar público fundado no município de Muriaé (Minas Gerais), denominado Grupo Escolar Silveira Brum (GESB). A investigação aqui problematizada, especificamente, aborda questóes relativas à criação $e$ consolidação do educandário, dando ênfase aos assuntos referentes às festividades escolares ocorridas no estabelecimento de ensino suprarreferenciado. O recorte temporal se justifica em virtude da data de fundação dessa instituição (1912) e o fim da Primeira República no Brasil (1930). Para a consecução do trabalho foram consultados documentos como relatórios do Grupo, ofícios e correspondências enviados à Secretaria do Interior, atas de eventos e outras fontes oriundas de visitas ao Arquivo Público Mineiro (APM), com sede em Belo Horizontel MG, e ao acervo existente na atual Escola Estadual Doutor Silveira Brum, em Muriaé/MG. Esta análise permitiu identificar que as comemoraçóes no Grupo atendiam aos interesses dos republicanos, que pretendiam se instituir no

1 Denilson Santos de Azevedo - Universidade Federal de Viçosa (UFV).

E-mail: dazevedo@ufv.br

2 Talitha Estevam Moreira Cabral - Universidade Federal de Viçosa (UFV). E-mail: talitha.cabral@ufv.br 
poder e difundir os ideais de civismo e amor à pátria no Brasil, no início do século XX.

Palavras-chave: História da educação; Grupos escolares; Festas escolares

\section{Abstract}

This paper discusses aspects related to the process of creation and the first years of operation of the first Public School Group founded in the city of Muriaé (Minas Gerais), called Grupo Escolar Silveira. Brum (GESB). Research problematized here specifically addresses issues related to the creation and consolidation of the breed, with emphasis on issues related to school festivities took place at the school cited. The time frame is justified because the date of the founding of this institution (1912) and the end of the First Republic in Brazil (1930). To the achievement of labor were consulted documents as Group reports, offices and letters sent to the Secretary of the Interior, minutes of meetings and other sources by visits to the Arquivo Público Mineiro (APM), based in Belo Horizonte/MG, and the existing acquis in current Escola Estadual Doutor Silveira Brum in Muriaé/MG. This analysis revealed that the celebrations in Group met the interests of Republicans, who wanted to be instituted in power and spread the ideals of good citizenship and love of country in Brazil, in the early twentieth century.

Keywords: History of education; School groups; School parties. 


\section{A CRIAÇÃO DO GRUPO \\ ESCOLAR SILVEIRA BRUM E \\ SEUS PRIMEIROS ANOS DE \\ FUNCIONAMENTO: RELAÇÓES \\ ENTRE A REPÚBLICA E AS FESTAS \\ ESCOLARES (1912-1930).}

O presente artigo apresenta alguns resultados da investigação sobre o processo de criação e os primeiros anos de funcionamento do primeiro grupo escolar público fundado no município de Muriaé (Minas Gerais), o Grupo Escolar Silveira Brum (GESB), criado em 1912. Com o intuito de analisar a cultura escolar produzida neste estabelecimento de ensino até a década de 1930, foram consultados documentos e outras fontes que tratam da trajetória do referido educandário, enfatizando a questáo das festas escolares, que supostamente representavam, naquele momento, uma tentativa de valorização dos preceitos republicanos.

A análise feita nesse trabalho permitiu identificar características da organizaçáo e do funcionamento da escola, bem como da cultura escolar instituída nos primeiros anos de sua criação e as práticas pedagógicas ali incorporadas e difundidas, especialmente por meio das festividades que ocorriam no ambiente escolar.

\section{A CRIAÇÃO E CONSOLIDAÇÃO DOS GRUPOS ESCOLARES NO BRASIL E SUA INFLUÊNCIA PARA O ENSINO PRIMÁRIO MINEIRO NO INÍCIO DO SÉCULO XX}

Muito já foi escrito sobre a formação dos grupos escolares no Brasil. Dentre os estudos que realizamos, o debate a respeito da criação e difusão desses educandários vêm sendo objeto de estudo por diversos pesquisadores em História da Educação nos últimos anos, tais como Carvalho (1989); Faria 
Filho (2000); Pinheiro (2002); Reis (2006). O acúmulo das investigações sobre essa temática tem propiciado a elaboração de balanços críticos e um volume considerável de publicaçóes. Essas reflexóes servem de referência e ponto de partida para a pesquisa que nos dispusemos a apresentar nesse texto.

Conforme a literatura sobre o assunto nos apresenta, no final do século XIX e início do século XX, um novo modelo de escola passou a vigorar no Brasil. A partir de 1889, com a instalação da república, o modelo educacional que vigorava até aquele momento, baseado no preceito das escolas domésticas ${ }^{3}$, passa a ser visto como ultrapassado e incapaz de atender aos ideais propagados pelos defensores do novo regime, como democracia, ordem, progresso e amor à pátria.

Os republicanos pretendiam, a partir desse momento, disseminar seus valores, preparando a criança para viver em uma sociedade capitalista. Segundo Corsetti (2002, p.2):

a política educacional dos republicanos buscou preparar o homem adequado ao processo de consolidação do capitalismo, para que os aspectos relacionados com a disciplina, o respeito à hierarquia e à autoridade, o controle rigoroso das atividades e o uso produtivo do tempo, bem como os demais valores decorrentes de uma prática com base nesses elementos, constituíram-se em "ingredientes" permanentes do cotidiano escolar.

Para atender aos intuitos propostos pelo novo modelo educacional, ocorre um movimento de renovação da escola primária por meio do surgimento dos grupos escolares. Essa transformação teve um profundo significado social, político e cultural visto que não representava apenas a "democratização" do acesso à leitura e à escrita, mas a implantação de uma

3 Nesse modelo educacional, as aulas aconteciam em ambientes cedidos e preparados pelos responsáveis, sem vínculo com o Estado. O pagamento do professor era de responsabilidade do contratante individual ou de um grupo de contratantes. (FARIA FILHO, 2000). 
instituição educativa responsável em difundir novos valores, hábitos e deveres.

O modelo "grupo escolar" representava um novo ideal de racionalização e uniformizaçáo do trabalho escolar, no que diz respeito a conteúdo, condutas, práticas pedagógicas, horário e cultura escolar; era uma tentativa de homogeneizar o currículo e fiscalizar o trabalho realizado nesses espaços.

Especificamente no estado de Minas Gerais, esses estabelecimentos de ensino foram criados no governo de Joáo Pinheiro, através da Lei no 439, de 1906. Na imprensa mineira, notas referentes à nova organizaçáo do ensino demonstravam a importância conferida à educaçáo nesse novo modelo educacional. A questâo da arquitetura dos prédios é bastante valorizada, a fim de demonstrar a centralidade conferida à educação nesse período.

Tão importante quanto a estrutura dos edifícios que sediavam os grupos escolares, eram as práticas difundidas nesse ambiente. Num discurso veiculado na Imprensa Oficial de Minas Gerais, um dos secretários do Interior escreve que:

A fusão de diversas escolas num só instituto,
subordinado a uma única direção traz, como
conseqüência, melhor orientação e mais suave
difusão do ensino, devido à especialização de
funções resultantes da divisão do trabalho de
cada docente. A aplicação da Lei econômica
da divisão do trabalho nos grupos escolares
apresenta os mais robustos resultados.
(MINAS GERAIS, 1913).

Essas transformações incluíram também o currículo das escolas. Saviani (2006) nos lembra que nos programas escolares foram reorganizadas várias disciplinas. Com a nova exigência curricular, modifica-se também a forma de ensinar. A nova metodologia adotada para esse modelo educacional foi denominada como método intuitivo ou lição das coisas, o qual implicava na adoção de um projeto concreto, racional e ativo de escolarização. 
Com tantas exigências, transformações e regulações, este modelo de escola se tornou referência naquele momento histórico, seja pela metodologia entáo adotada ou pelo modo de organização da prática pedagógica, com a racionalização do trabalho e a divisão de tarefas, seja pela estrutura tida como adequada para as atividades escolares, obedecendo às prescriçóes sanitaristas e higiênicas.

Feitas essas breves consideraçóes acerca da criação dos grupos escolares no Brasil, percebe-se, portanto, que as práticas difundidas com a criação desses educandários em Minas Gerais, tendo como pano de fundo no caso desta pesquisa o GESB, foram fundamentais para a consolidação de uma nova maneira de se fazer a escola primária. E é nesse sentido que abordaremos a seguir aspectos referentes ao cotidiano do grupo escolar muriaeense, enfatizando as comemoraçóes ocorridas no interior dessa instituição de ensino nos anos de 1912 a 1930.

\section{GRUPO ESCOLAR SILVEIRA BRUM: AS RELAÇÓES ENTRE A REPÚBLICA E AS FESTIVIDADES ESCOLARES}

O modelo educacional da cidade de Muriaé praticamente não se difere das demais propostas recomendadas a partir da criação dos grupos escolares. Tanto no que diz respeito à organização do trabalho, bem como na sistematização das práticas pedagógicas difundidas no espaço escolar, inclusive no que diz respeito à realização das festividades escolares. Para compreender melhor essa situação, analisaremos alguns aspectos dos primeiros anos de funcionamento do GESB que nos forneceram pistas para compreender como estavam ocorrendo as situaçóes de comemoraçóes nesse Grupo.

Criado pelo decreto 3.305, de 5 de setembro de 1911, o GESB foi inaugurado em 07 de agosto de 1912 sob a direção do professor José Gonçalves Couto, que depois de nomeado por ato do Sr. Governador do Estado, Júlio Bueno Brandão, em 12 de janeiro de 1912, permaneceu no cargo até 13 de abril de 1936, quando se aposentou. 
A respeito da estrutura do Grupo Escolar Silveira Brum, a Revista de Historiografia Muriaeense (1979) aponta que o edifício sobressaía-se como um dos melhores prédios da cidade. Criado exclusivamente para o fim da instrução, o prédio foi edificado dentro do conjunto arquitetônico da Praça Coronel Pacheco de Medeiros, um dos principais pontos de referência da cidade no início do século XX.

Abaixo podemos ver uma foto do Grupo durante os primeiros anos de funcionamento:

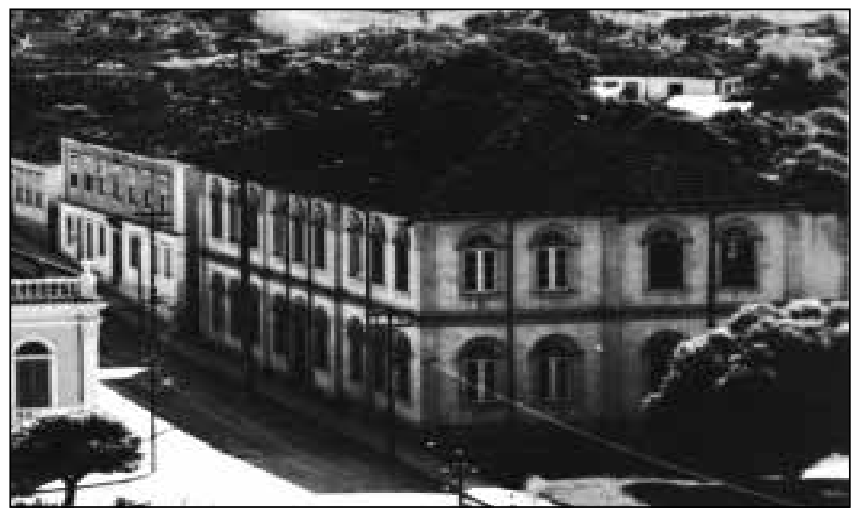

Figura 1: Prédio do Grupo Escolar Silveira Brum (1916) - Fonte: Arquivo Municipal

$\mathrm{Na}$ continuidade da análise dos documentos encontrados, como os diversos relatórios escolares, bem como em relatórios de visitas de inspeção, percebemos que o primeiro diretor, José Gonçalves Couto, cumpria as tarefas a ele designadas. Nos ofícios enviados à Secretaria do Interior percebemos a distinta atençấo dada às questôes relacionadas com as práticas pedagógicas, de modo a garantir que a disciplina e a ordem fossem cumpridas nas salas de aula.

Também encontramos, em um relatório datado de 28 de dezembro de 1912, a descrição do método pedagógico desenvolvido no GESB. Neste trecho foi possível identificar como as liçóes de coisas proposta pelo método intuitivo estava sendo trabalhada. A equipe de visitantes particulares escreveu que o educandário se configurava como um exemplo de modelo escolar: 

se casam os melhores mhetodos pedagógicos com a mais séria disciplina e ordem. As licções ministram-se por processos brandos e altamente profícuos fiados na intuição e analyse dos factos múltiplos que constituem a essência da escola moderna. A noção das coisas caminha da mais simples para a menos complexa, ensinando a mente infantil para dellas se apreender suavemente para a vida independente e autônoma do individuo na sociedade [...] nunca imaginamos que em quatro escassos mezes de aulas tanto se conseguisse de resultados esplendidos nesta casa [...] (RELATÓRIO DE VISITA DE PARTICULARES, 1912, s/p).

Não obstante, a respeito de algumas informaçóes contidas nos documentos pesquisados, cabe salientar que esses materiais são aliados importantes na construção da realidade cotidiana do Grupo. No entanto, é conveniente que tenhamos cautela na análise desses escritos localizados pelo fato de que, algumas informaçóes localizadas, podem ser tendenciosas no sentido de exaltar em demasia determinados aspectos positivos e tapar as lacunas e problemas existentes no estabelecimento, pois nem sempre foi possível identificar, com a leitura do material localizado, quem eram essas pessoas que documentavam as informações. É necessário, então, que se acrescentem os demais elementos obtidos dos variados materiais estudados, elaborando um paralelo e um comparativo do que poderá ou não ser o mais próximo da realidade, haja vista que, em se tratando de história, torna-se uma tarefa complexa resgatar completamente uma realidade, sem que fiquem dúvidas e/ou outras consideraçóes a serem analisadas a posteriori.

Apesar dessa dificuldade da área, podemos nos apropriar de algumas informaçóes pesquisadas para tentar explicar uma dada situação. Nesse sentido, no que tange aos professores que atuaram no ensino primário do GESB, podemos inferir através dos documentos investigados que, em sua maioria, possuíam 
formação de normalistas, obtidas nas Escolas Normais do Estado e do próprio município.

Foi possível perceber que o acesso e a ascensão na carreira profissional do magistério dependia tanto da competência profissional quanto da influência política e pessoal do docente pois na cidade de Muriaé os contratos não se davam apenas por indicações políticas, mas também eram resultado dos concursos realizados pelo Grupo. Como se supóe do documento localizado no Arquivo Público Mineiro, que apresenta um concurso de "Uma vaga adjuncto - Grupo Escolar de S. Paulo do Muriahé Interior, 6a secção, 27-XI-1917".

Após a contratação e antes de iniciar o trabalho docente no Grupo, os professores deveriam apresentar sua origem familiar e atestar sua boa conduta moral e sanidade física. Nos documentos consultados, esses três tipos de declaraçôes eram pré-requisito para o exercício de seu cargo: atestado de bons antecedentes criminais, de boa saúde e de filiação. O corpo de profissionais compunha-se, inicialmente, de oito professores da cidade, muitos lecionando gratuitamente.

Sobre a rotina escolar da instituição, ainda no primeiro relatório escrito pelo diretor José Gonçalves Couto à Secretaria do Interior, são apontadas características desse cotidiano, determinadas através de uma programação regrada e préestabelecida:

De 12 de agosto a 22 de janeiro de 1913, diariamente às 10,50 foi encerrado o ponto de entrada dos professores [...].

Das 10,50 as 11 assistiam, em posição militar corretíssima, ao hasteamento da bandeira [...] Um alumno, previamente designado por mim, saudava com enthusiasmo a bandeira, terminando sempre a sua saudaçáo com um vibrante Viva ao pavilhão Nacional, no que era compreendido pelos colegas. Às 11 em ponto, já em classe, feita a revista, começavam as professoras os seus trabalhos escolares. 
Denilson S. de Azevedo Talitha Estevam M. Cabral

No dia 22 de janeiro de 1913, de acordo com o artigo 291 parágrafo único do regulamento vigente, passaram as aulas a funcionar das 7 às 11 da manhâ, seguindo-se a mesma ordem referida.

Os exercícios physicos são feitos no pateo do edifício [...].

Nos 10 minutos de recreio, durante o qual sáo os alumnos fiscalizados por dois professores que se revezam durante a semana, os rapazes passam para um pateo [...] separado por uma tella de arame. (RELATÓRIO DO MOVIMENTO ESCOLAR, 1913, s/p).

Nesse excerto é interessante perceber a exaltação que era feita ao elemento patriótico, representado - nesse caso - pela bandeira nacional. Diariamente, os alunos eram convidados a reverenciá-la, o que nos permite supor que, essa ação, era uma maneira de reforçar o caráter nacionalista e republicano do novo modelo educacional.

Essa exaltação dos ideais de "Ordem e Progresso" trazidos pela República são identificados em diversos outros momentos no GESB. Outro documento que indica a disseminação dos ideais republicanos é um relatório de visita de particulares, em que um dos visitantes escreve:

Depois de percorrermos todos os salóes de estudo, onde apreciei graciosos e complicados trabalhos manuaes, e outras cousas, soou, eloquentemente, a sineta que nos annunciava o recreio infantil. Instantes depois passava, em formatura elegante, a alegre criançada. A nota destaque do momento foi a continência á bandeira nacional. $O$ que mais me admirou foi o respeito com que [...] saudaram o auriverde pendâo. [...] todos os apparelhos exigidos pela pedagogia hodierna alli se encontram, no mais perfeito estado de asseio e conservaçáo, prestando os seus relevantes serviços á causa da vida pratica [...] a mnemotechnia é observada com todo 
o rigor [...] (RELATÓRIO DE VISITA DE PARTICULARES, 1913, s/p).

Outro momento específico de exaltação dos preceitos republicanos diz respeito às festividades escolares. Nos relatórios anuais localizados podemos perceber que as datas da Independência do Brasil e da Proclamação da República sempre eram muito comemoradas.

De acordo com Roger Chartier (1987) a realização de festas cívicas foi impulsionada por meio da Revoluçáo Francesa. Essas comemoraçóes revolucionárias carregavam em si um interesse pedagógico de complementar a educação escolar formal, além de garantir a formação integral do sujeito, baseada na educabilidade natural do homem.

As festas escolares do Grupo Escolar Silveira Brum aconteciam com frequência desde a sua fundação. Eram momentos que estavam intimamente relacionados às datas cívicas e aos princípios patrióticos, e que pretendiam refletir o movimento comum a outros grupos escolares mineiros que aproveitavam destas solenidades para disseminar os ideais republicanos.

No educandário suprarreferenciado até o espaço foi pensado para a realização dos eventos escolares, conforme se infere de documento localizado no arquivo da atual Escola Estadual Doutor Silveira Brum:

Os seus salóes, em número de doze: oito para as aulas, um para o gabinete do director, um para o museu escolar, outro o nobre - destinado à reunião dos alumnos nos dias de festas escolares, $\mathrm{e},(.$.$) o vestíbulo$

(...) são vastíssimos e mui bem arejados.

(...) (RELATÓRIO DO MOVIMENTO ESCOLAR, 1913, s/p, grifo nosso).

Sobre as festividades, de acordo com o relatório do diretor, o dia da inauguração do prédio escolar foi marcado de muitas comemoraçôes, com a presença de pessoas ilustres:
A criação do grupo escolar silveira brum

e seus primeiros anos

de funcionamento:

relaçōes entre a república

e as festas escolares

(1912-1930).
Educ. Foco, Juiz de Fora, 175 v. 20, n. 3, p. 165-186, 
Denilson S. de Azevedo Talitha Estevam M. Cabral

A este acto, que se reveste de toda a solenidade, compareceram quasi todas as auctoridades locaes, a câmara municipal incorporada e muitas famílias. O governo foi representado pelo Exmo. Sr. Dr. Antonio da Silveira Brum.

[...] Ao acto da installação compareceram, dos 568 matriculados, 420 alumnos. No dia 7 deste, ao meio dia, houve a solennidade da bençáo do prédio pelo Revmo. Sr. Pe. João Pio, que pronunciou bella allocução. A este acto, compareceram muitas pessoas gradas. [...]

Usando da palavra, o Sr. Silveira Brum agradeceu [...] as manifestaçóes de apreço que lhe foram dirigidas [...] e me fez a entrega do prédio. Recebendo-o, agradeci a preciosa dádiva, promettendo enviar todos os meus esforços para que o Grupo, que é um dos primeiros do Estado, quanto ao prédio, o seja também, quanto a parte intellectual e moral [...]. Os alumnos cantaram o "Hymno a Tiradentes" [...] O Sr. Inspector escolar, depois de varias consideraçóes sobre a instrução, tratou de fundar a Caixa Escolar, que recebeu o nome de V. Excia [...]

Ás seis da tarde, encerrou-se a sessão, retirando-se em seguida todos os alumnos e convidados .[...] (RELATÓRIO DO DIRETOR, 1912, s/p)

Em outro relatório enviado à Secretaria do Interior no ano de 1914, o diretor, Gonçalves Couto, relata que "algumas datas nacionaes, foram festivamente comemoradas" e apresenta que:

O ensino primário era ministrado em quatro anos, com um programa enciclopédico com matérias que proporcionavam uma educação integral - a educação física, intelectual e moral. Previa a utilizaçáo do método intuitivo [...] Exigia-se uma obediência, etc.). O tempo escolar passou a ser controlado através do calendário. Havia também práticas "ritualizadas" 
e "simbólicas", como os exames finais, as exposiçóes escolares, as datas cívicas e as festas de encerramento do ano letivo. (RELATÓRIO DO DIRETOR, 1912, s/p, grifo nosso).

Nesse trecho, é possível perceber que as festividades no Grupo representavam mais uma forma encontrada pelo diretor da escola para desenvolver, através de práticas "ritualizadas" e "simbólicas", os ideais republicanos.

Num outro documento consultado, Gonçalves Couto informa que os dias 7 de setembro e 19 de novembro foram festejados no GESB, datas referentes à Independência do Brasil (7 de setembro) e Proclamação da República (15 de novembro), respectivamente. No relatório sobre a festa de 7 de setembro, em 1913 (segundo ano de funcionamento do Grupo), o diretor evidencia o patriotismo por meio de uma comemoração à independência do Brasil que

(...) Recebendo o mastro, que foi colocado à frente do Grupo Escolar, e a bandeira, que também foi confeccionada na Alemanha, agradeci em nome do governo a preciosíssima offerta. Em seguida, ao som do hymno nacional tocado pela corporação musical 7 de setembro -, e entoado, vibrantemente, por todos os alumnos do grupo, elevou-se lentamente, garbosamente ao grande mastro a bandeira nacional que foi saudada por uma salva de 21 tiros. (RELATÓRIO DO MOVIMENTO DO GRUPO ESCOLAR DE MURIAÉ, 1913, s/p).

Em 1915, temos que:

o dia 7 de agosto - aniversário do grupo - 7 de setembro e 19 de novembro foram mais solenemente festejados. No dia 19 deste mez houve a solennidade da entrega de certificados de approvaçação dos alumnos que concluíram o curso. (RELATÓRIO DO DIRETOR, 1915, s/p). 
Nesse relato, temos que a data da proclamação da República também foi festejada (quatro dias depois) para findar o ano letivo das crianças aprovadas. Já no relatório de 1919, o diretor cita outras datas que também eram comemoradas no estabelecimento de ensino:

Como nos annos anteriores,
commemorando-se nesta casa de ensino,
durante o anno a que se refere este relatório,
as grandes datas normaes. Os dias 21 de
abril, 7 de agosto - anniversario do grupo, -
e 7 de setembro foram festejados com maior
solennidades [...]. (RELATÓRIO DO
DIRETOR, 1919, s/p).

Outra festa que ocorrera no educandário muriaeense era a chamada "Festa da Árvore", que costumava acontecer em outras localidades mineiras, com influência internacional de modelos de festas que existiam em países norte-americanos e europeus. No exterior, essa iniciativa acontecia através do plantio de árvores e palestras sobre a importância da natureza, a fim de mobilizar os cidadãos para o cuidado ambiental de seus países. Aqui no Brasil, segundo Rodrigues (2010, p.101),

a Festa da Árvore consistia numa sessão solene em que era explicado o significado da festa, com palavras repassadas de muito carinho e amor às árvores (como se se operasse a transformaçáo de um objecto profano, a árvore, em sagrado, sendo o sagrado o retorno da intimidade entre o homem e o mundo, entre o sujeito e o objecto). Recitavam-se versos e cantavamse cançôes patrióticas durante a marcha que decorria desde a escola até ao local onde eram plantadas as árvores, que eram tidas como elos de ligaçáo entre o tempo passado e o tempo vindouro. 
E é com esse pensamento que, em 1917, o diretor aponta as comemoraçóes do dia da Independência fazendo referência à festa da Árvore:

Em comemoração da data da independência da nossa Patria, foram celebradas a festa das arvores, como determina V. Excia em portaria de 24 de agosto p. findo, e a das aves, como em completivo da 1 a;

Foi executado o seguinte programma:

Ás $12 \mathrm{~h}$ - Dissertação dos professores, cada um em sua classe, sobre o 7 de setembro;

Ás 12 1/2h - Allocução do director sobre as arvores e a celebração da festa das mesmas;

Ás $2 \mathrm{~h}$ - Plantio de arvores no pateo do estabelecimento por professores e alumnos [...]

Durante a plantação - Hymnos "A Independência" e "A Bandeira".

Ás $21 / 2 \mathrm{~h}$ - Liberdade aos pássaros trazidos pelos alumnos para este fim;

Ás $3 \mathrm{~h}$ - Distribuição de prêmios aos alumnos que, em procedimento, aproveitamento e assiduidade mais se distinguirem em agosto p. findo. (RELATÓRIO DO DIRETOR, $1917, \mathrm{~s} / \mathrm{p})$.

Detalhes como estes citados nos excertos supracitados, percebidos durante as comemoraçóes realizadas no Grupo, como o hasteamento da bandeira nacional, hinos patrióticos cantados em continência e aclamaçôes aos poderes públicos, nos revela aspectos civilizatórios que foram, ao longo do tempo, incutidos nos alunos, fazendo com que sentimentos como o de amor a Pátria estivessem sempre relacionado à formação do indivíduo.

Quanto a isso é possível entender que as festas cívicas e o hasteamento da bandeira nacional eram pensados pelos grupos escolares como um espetáculo formativo de sensibilidade
A criação do grupo

escolar silveira brum

e seus primeiros anos

de funcionamento:

relaçōes entre a república

e as festas escolares

(1912-1930) 
patriótica e de respeito ao regime republicano. Deve-se a isso, possivelmente, a intensa preocupação em festejar as datas marcantes na organização da República.

Isso porque, mediante toda a nova organização do ensino, enquanto local de disseminação dos preceitos republicanos, criava-se também a idéia de uma memória nacional, que era buscada por meio das festividades escolares. Nas palavras de Rodrigues (2010, p.95):

As festas contribuem para a constituição de um modo de construir e difundir referências e símbolos nacionais, integrando a memória coletiva nacional. Em momentos de tensão e ruptura históricas, as festas são organizadas para criar consensos e unir o povo a um ideal, conquistando a adesão do mesmo para novas propostas políticas e consolidando uma nova ordem social.

A respeito dessas comemoraçóes, Vieira e Marcusso (2009, p.2) nos informam que:

Previstas no regulamento da Instrução Pública de Minas Gerais, e também de outros estados, eram momentos de evidência local para os Grupos Escolares, com a divulgaçáo das açôes republicanas e dos símbolos da República (bandeira, escudo e hino). Aconteciam com certa frequência, e por reunirem a comunidade escolar tornavam-se uma oportunidade de exaltação da escola e das autoridades presentes.

Bencostta (2005) nos aponta que existia uma preocupação em inculcar consciências patrióticas nos discentes através dessas festas. Assim, calendários normatizadores foram instituídos para que se comemorassem datas cívicas. De acordo com Faria Filho (2000, p. 86):

o hasteamento da bandeira, as festa cívicas e mesmo a inauguração dos grupos escolares eram momentos organizados e pensados 
como espetáculos formativos, não apenas de comportamento, mas de sensibilidade e sentimentos em face da cidade, do regime republicano, da cultura das classe pobres, dentre outros.

Ainda mediante as informações trazidas pelos relatos apresentados anteriormente, percebemos a magnitude concedida às datas cívicas do calendário. Essa era uma maneira de dar visibilidade às novas práticas pedagógicas implementadas nos novos modelos escolares. Indo ao encontro das idéias de Faria Filho, Lopes (2011, p.2) aponta que:

em que pese as multiplicidades de usos, intencionalidades e sentidos existentes nas festas, estas eram utilizadas pelas escolas reunidas e grupos escolares, especialmente, para tornar mais visível sua ação pedagógica no contexto escolar, demarcando sua posição de importante inovaçáo no aparato escolar existente. Reunião e movimentação de um número significativo de alunos, as festas escolares demarcavam mobilidade e status das escolas na cidade. Assim, os grupos escolares, no período analisado, situados no topo da hierarquia do sistema de ensino primário, participavam crescentemente das festividades públicas. Seus alunos passavam, cada vez mais, a figurar nas solenidades públicas discursando em nome delas.

$\mathrm{Na}$ continuidade das análises dos documentos pesquisados, foi possível inferir que as festividades de fim do ano no GESB, na maioria das vezes, se distinguiam das demais comemoraçóes do ano. Existia uma fiscalização que visava avaliar os resultados das tarefas realizadas no estabelecimento, e se estas estavam de acordo com as disposiçóes legais. Não obstante, assim como as outras festas, esta devia ser registrada e divulgada na cidade a fim de fortalecer os ideais republicanos de desenvolvimento, ordem, progresso e amor à pátria. 


\section{CONSIDERAÇÓES FINAIS}

A construção desse trabalho apoiou-se nos estudos dos teóricos da História da Educação Brasileira, particularmente os trabalhos sobre a criação dos grupos escolares no Brasil e em Minas Gerais. O cotejamento dos dados nesse artigo priorizou o estudo sobre as festividades escolares no início do século passado.

Os resultados obtidos demonstram que a criação do Grupo Escolar Silveira Brum na cidade de Muriaé foi o marco inicial de um modelo de escolarização que surge em todo o país, incluindo o estado de Minas Gerais. No referido município, o educandário criado pretendia atender às exigências da república, com a divisão do trabalho, de modo a controlar os espaços e tempos escolares.

A nova metodologia de ensino utilizada contava com a figura do diretor como responsável pela organização do trabalho, com a presença de um professor como regente do ensino elementar a um grupo de alunos divididos por séries no ensino primário.

Essas modificações nas práticas escolares contribuíram para concretizar uma aprendizagem progressiva, com a gradativa implantação de um trabalho pedagógico cada vez mais embasado nos princípios republicanos e patrióticos. À guisa de exemplificação podemos compreender as festividades escolares como modos de disseminar os preceitos republicanos na sociedade brasileira naquela época.

Nesse viés, a pesquisa mostrou no GESB havia o esforço de tentar alcançar o ideal de nação civilizada e de identidade nacional proposto com a proclamação da República. É possível inferir que as comemoraçóes no Grupo representava o progresso da nação, e contribuía para a construção de um imaginário político voltado para os interesses republicanos capitalistas.

Desse modo, o estudo realizado nos leva a crer que a orientação dos currículos escolares hoje são reflexo da 
sociedade em que vivemos, assim como no início do século passado o programa educacional estava voltado para os interesses republicanos, que se externaram por meio das festividades escolares. E, nesse sentido, a história da educação auxilia na compreensão de questôes atuais, não com o intuito de solucionar os problemas que surgem, mas, com a intenção de lançar luz a aspectos já vivenciados em outros momentos históricos, capazes de orientar possibilidades e caminhos.

\section{REFERÊNCIAS}

Documentos pesquisados em Arquivos:

GRUPO ESCOLAR SILVEIRA BRUM. Atas de Instalação, posse, exames, etc. (Arquivo Escola Estadual Doutor Silveira Brum), 1912-1924

GRUPO ESCOLAR SILVEIRA BRUM. Ofícios enviados e recebidos da Secretaria de Educação do Estado. (Arquivo Escola Estadual Doutor Silveira Brum), 1912 a 1930.

GRUPO ESCOLAR SILVEIRA BRUM. Termos de Visitas Oficiais; Termos de Visitas Particulares. (Arquivo Público Mineiro e Escola Estadual Doutor Silveira Brum), 1912-1927.

GRUPO ESCOLAR SILVEIRA BRUM. Cadernos de avaliação e certificados de aprovação dos alunos. (Arquivo Escola Estadual Doutor Silveira Brum), 1913-1916.

GRUPO ESCOLAR SILVEIRA BRUM. Relatório do Diretor. (Arquivo Escola Estadual Doutor Silveira Brum), 1913-1919.

GRUPO ESCOLAR SILVEIRA BRUM. Atas de Instalação e Exames; Relatórios do diretor; Termos de Assentamento e Posse; Visitas Oficiais e Particulares; diplomas; requerimentos; nomeações; decretos; licenças; procurações; frequência dos professores e/ou alunos. (Arquivo Público Mineiro), 1912-1930.

Revista de Historiografia Muriaeense. Ano II, no 2 Muriaé/MG. Maio, 1979.
A criação do grupo escolar silveira brum e seus primeiros anos de funcionamento: relaçōes entre a república e as festas escolares (1912-1930).
Educ. Foco, Juiz de Fora, 183 v. 20, n. 3, p. $165-186$ nov. $2015 /$ fev. 2016 
MINAS GERAIS. Secretaria do Interior e Justiça. Relatório da Imprensa Oficial. (APM), 1913.

Livros, artigos e periódicos:

BENCOSTTA, M. L. A. Grupos escolares no Brasil: um novo modelo de escola primária. In: BASTOS, M.H.C. \& STEPHANOU, M. (Orgs). Histórias e Memórias da Educaçáo no Brasil. Petrópolis: Vozes, p. 68-76, 2005.

CARVALHO, M. M. C.de. A escola e a República. São Paulo: Brasiliense, 1989.

CHARTIER, R. Lectures et lecteurs dans la France d'Ancien Régime. Paris: Éditions du Seuil, 1987.

CORSETTI, B. A escola pública no Rio Grande do Sul e o projeto político republicano (1889/1930): a escola pública, a formação de professores e o controle disciplinar. In: Congresso Brasileiro de História da Educação: História e Memória da Educaçáo Brasileira, 2, 2002, Natal. Anais. Natal: Núcleo de Arte e Cultura da UFRN, p. 1-12, 2002.

FARIA FILHO, L. M. de. Dos Pardieiros aos Palácios - Cultura escolar e urbana em Belo Horizonte na Primeira República. Passo Fundo: UPF, 2000.

LOPES, A.C.Aescolaem festa: Festividades escolaresnaI República no Piauí. Disponível em: http:<//www.faced.ufu.br/ colubhe06/anais/arquivos/396AntonioPaduaCarvalhoLopes. pdf> Acesso em: 15 nov. 2012.

PINHEIRO, A.C.F. Da era das cadeiras isoladas a era dos grupos escolares na Paraíba. Campinas, SP: Autores Associados; São Paulo: Universidade São Francisco, 2002.

REIS, R.M. dos. A história dos Grupos Escolares em Mato Grosso. In: Congresso Brasileiro de História da Educaçáo - A Educaçáo e seus sujeitos na História, 4, Goiânia. Anais. CD-ROM, 2006.

RODRIGUES, M.M.P.F. Festas escolares: as festas da árvore no Barreiro. História da Educaçáa, Pelotas, v. 14, n. 31, p. 95-119, maio/ago 2010. 
SAVIANI, D. O legado educacional do "longo século XX” brasileiro. In: SAVIANI, D.; ALMEIDA, J. S.; SOUZA, R. F. de; VALDEMARIN, V. T. O legado educacional do século XX no Brasil. Campinas: Autores Associados, 2006.

VIEIRA, L.C. \& MARCUSSO, M.F. As comemoraçôes escolares e suas frestas: as relaçóes entre a república e as festas do Grupo Escolar de Mariana (1909-1930). In: Congresso Iberoamericano de História da Educaçáo Latino-americana, 9, 2009, Rio de Janeiro. Anais, p. 1-7, 2009.

Data de recebimento: agosto de 2014 Data de aceite: junho de 2015 